\section{Limiares e fronteiras de uma cidade que ainda vive}

\author{
Lázaro Batista \\ Luis Antonio dos Santos Baptista
}

\section{RESUMO}

O artigo discorre sobre as articulações entre subjetividade e experiência urbana à luz das categorias de limiar e fronteira de Walter Benjamin. Enquanto a fronteira designa uma linha que tem por princípio de funcionamento conter e manter algo, evitando seu transbordamento e definindo limites, o conceito de limiar se inscreve noutro registro que se notabilizaria por permitir que se transite, com considerável facilidade, de um lugar a outro diferente e, por vezes, mesmo oposto. Ainda que também separe dois territórios, diferente da fronteira, o limiar permite transitar por entre eles. Dessas categorias são ressaltados os sentidos peculiares de tempo e de espaço produzidos pela história, assim como os desafios políticos ensejados por elas para a problematização das práticas de poder sobre a alteridade no capitalismo contemporâneo. Como conclusões, a modulação entre fronteiras e limiares no espaço urbano nos serve de indicativo para afirmar que, latejante por meio dos seus poros, mediante as passagens que a faz respirar, a cidade ainda vive.

Palavras-chave: Limiar; Fronteira; Cidade

\section{ABSTRACT}

\section{Thresholds and boundary of a city that still lives}

This article discusses the connections between subjectivity and urban experience under the light of Walter Benjamin's definitions of thresholds and boundary. While the concept of boundary designates a line that serves to contain and maintain something, avoiding its overflow and defining limits, the concept of threshold would be notable for allowing one to move with considerable ease from one place to another different and sometimes even opposite place. Although it also separates two territories, the threshold allows to transit through them, unlike the boundary. From these definitions, we emphasize the peculiar understanding of time and space produced by history, as well as the political challenges conceivable by them, in order to question power practices regarding alterity in contemporary capitalism. As a conclusion, the modulation between boundaries and thresholds in urban space acts as an indication to affirm that, throbbing through its pores, through the passages that make it breathe, the city still lives.

Keywords: Threshold; Boundary; City

Percorrida a pé, ou sobrevoada, uma estrada, ou uma cidade, impõe forças diferentes a quem a observa. Modulações do corpo do observador no percurso em terra firme afirmam o que acontece ao redor; modulações a indicar os efeitos do que é, o que foi, e o que não deveria ser uma cidade. As forças impostas não permitem o repouso do corpo de quem a percorre.

Só quem percorre a estrada a pé sente o seu poder e o modo como ela, a cada curva, faz saltar do terreno plano (que para o aviador é apenas a extensão da planície) objetos distantes, miradouros, clareiras, perspectivas, como a voz do comandante que faz avançar soldados na frente de batalha (Benjamin, 2004, p.14).

No chão, segundo o filósofo berlinense, o corpo é convocado a se contagiar e a se transtornar no percurso; convocação que o torna vulnerável ao desestabilizador encontro com a ra-

\section{Sobre os Autores}

L.B.

orcid.org/0000-0002-3224-411X Universidade Federal de Roraima - Boa Vista, RR lazaro.batista@ufrr.br

L.A.S.B.

orcid.org/0000-0002-5693-0747

Universidade Federal

Fluminense - Niterói, RJ

baptista509@gmail.com

\section{Direitos Autorais}

Este é um artigo de acesso aberto e pode ser reproduzido livremente, distribuído, transmitido ou modificado, por qualquer pessoa desde que usado sem fins comerciais. 0 trabalho é disponibilizado sob a licença Creative Commons CCBY-NC.

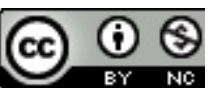


dicalidade da empiria. A observação no solo provoca heterogêneos enfrentamentos; "faz saltar do terreno plano" (Benjamin, 2004, p.14) o acaso, o sobressalto, o imprevisível. Do olho é subtraído o poder soberano da análise. Fronteiras, limites, territórios vazios perdem a clareza da visibilidade; correm o risco de surpreender o pedestre. Horizontes, portas, muros, grades, fios elétricos, poderão pôr em dúvida convicções do passante, recusá-las, não dizer nada; terão o poder também de afırmar o que ele seja, ou o que ele não deveria ser, o que deve evitar. Dar sentido ao que seja a alteridade seria outra função desses objetos a aludir espaços fronteiriços. Inútil seria definir o outro tendo como referência o perceptível. Fronteiras edificadas para incluir, ou excluir, fundamentadas nos atos de proteger, cuidar, encarcerar, são estranhadas quando o corpo se modula no contato com o solo.

Próxima das nuvens, a urbe se silencia, é inodora, se mantém homogênea ao retratar a ordem do seu traçado. A serenidade perdura na paisagem. A voz de comando é emitida da pacificada racionalidade do olhar. A "frente de batalha" é neutralizada. O sujeito da observação se mantém incólume ao vislumbrar a paisagem. Vista de cima, linhas a delimitar fronteiras e limiares se assemelham às percebidas nos mapas onde inexiste a provisoriedade de uma forma, a conflitualidade da vida cotidiana, paradoxos. Dos territórios são omitidos o terror e as lutas que edificaram os seus limites. A cidade contemplada do céu corre o risco de agonizar. Quem a observa do solo não tem tal percepção. A transtornadora presença da empiria faz da urbe o lugar das heterogêneas sensações, do acaso, da força da alteridade que exigem o desassossego de algo vivo.

Do alto, um campo de extermínio, um bairro, uma avenida, limites de um país, um cemitério, uma floresta, ruínas de uma cidade possuem a clara delimitação do tempo e do espaço para reconhecê-los. Caso o olhar do observador se perca no sobrevoo terá a serenidade dos mapas para acompanhá-lo na travessia. Espaços da exclusão, da inclusão salvadora, zonas perigosas, áreas educativas de uma cidade se mostram ao olhar do alto como se a "frente de batalha" faltasse; o mundo estivesse em paz; as artes de combate estivessem ausentes da feitura das suas margens.

Na cidade percorrida a pé, o conforto doado pela cartografia serena é interrompido. Corpo, sujeito da observação, paisagem terão seus contornos alterados a qualquer momento. Na travessia, "a cada curva faz soltar do terreno plano, objetos distantes" (Benjamin, 2004, p.14), de tempos outros, a turvar a delimitação clara do espaço e do tempo dos calendários e dos mapas. Campos de extermínio, ruínas, parques, residências, cemitérios de ontem e de hoje perderiam a impermeabilidade das suas bordas. Paredes, grades, portas, ganham a porosidade dos corpos que pulsam. As funções in- questionáveis destes artefatos fracassam. A cidade ainda vive, ainda lateja por meio dos seus poros, através das passagens que a faz respirar? Que subjetividades emergiriam das cidades onde as bordas das suas fronteiras e limiares são produzidas por frentes de combates?

No relato sobre a vila Svolvaer, na Noruega, Benjamin indica um som peculiar que ressoa na madrugada em suas ruas:

As ruas de Svolvaer estão vazias. E por trás das janelas as persianas de papel estão fechadas. Estarão as pessoas a dormir? Passa da meia-noite; numa das casas ouvem-se vozes, noutra ruídos de uma refeição. E cada som que ressoa na rua faz desta noite um dia que não figura no calendário (Benjamin, 2004, p. 205).

$\mathrm{Na}$ vila dos mares do hemisfério norte, tempos, gestos, histórias díspares atravessam a janela. Ocupam a rua indefinidos, ambíguos, entrecortados; aludem que algo de vivo ainda sucede. Burlam a conclusividade de uma data, de um espaço, de uma diferença na recusa de ilustrarem mapas ou calendários. 0 ressoar dos sons fora das paredes das residências indica a falência das fronteiras que apartam perigos de alegrias, morte da vida, como se os espaços fossem blindados e imaculados. Através das persianas algo perpassa; a cidade invade recantos do privado, ganha outras formas que atravessam sonhos, modos de despertar. Ela também poderá ser negada, expulsa, mas persistirá como um fora incômodo com suas formas sempre provisórias. À luz do relato do filósofo berlinense, o que passa e o que se passa por detrás de uma janela fechada, ou de uma fronteira? Que ruídos poderiam ser ouvidos na madrugada das ruas das grandes cidades brasileiras?

Do alto, cidades brasileiras exibem a contrastante paisagem. Florestas, favelas, condomínios à beira mar, escombros de fábricas do passado, monumentos, centro histórico, arquitetura moderna, bairros populares são percebidos ao som do silêncio. No sobrevoo destas cidades nada é ouvido, a urbe não fede, não exala nenhum odor. A urbe apresenta-se à semelhança de um cartão postal, de uma ideia, de uma imagem sem corpo. Suas fronteiras são claras, impermeáveis e sólidas. O tempo diferenciado das construções compõe a clareza da paisagem: passado, presente, futuro pedagogicamente indicam a continuidade da história. A beleza, a miséria, a harmonia, o perigo, o passado restaurado do centro histórico, o viver protegido dos condomínios podem ser vistos do alto. Cada coisa no seu devido lugar. O olhar próximo das nuvens observa a violência localizada, o mapeamento nítido do que passou, do que sucede e o que deverá acontecer no amanhã. Das nuvens, os lugares ditos perigosos, as zonas violentas, não exigirão ao pensamento a problematização do que seja o perigo. A violência é claramente detectada como se em outros locais a paz residisse. A urbe vista do alto se exime dos 


\section{INTERACÃO EM LF PSICOLOGIA}

paradoxos produzidos por tempos e espaços díspares que se justapõem nervosamente como uma "frente de batalha". Que subjetividades habitariam o solo de uma cidade quando o poder do seu mapa fracassa em mostrar a potência dos seus paradoxos? Quais fronteiras habitariam e teceriam as almas dos seus citadinos? O que pode um limiar?

\section{PASSAGENS ENTRE LIMIARES E FRONTEIRAS}

No esforço de uma apreensão conceitual, recorremos a um dos pequenos textos que compõem a obra inacabada Passagens, de Walter Benjamin (2006). Esse autor sustenta que as tradicionais transições relacionadas, por exemplo, à morte, à puberdade ou matrimônio, se mostram atualmente desgastadas ou desvalorizadas. Delas, o filósofo berlinense acredita que tenha nos restado apenas a experiência transitória do adormecer-despertar. "Tornamo-nos muito pobres em experiências liminares" (p. 535), dirá ele, tomando essa pobreza como indício sintomático de um tempo que exigiria de nós separações dicotômicas, invariâncias, certezas. Tempo desdobrado, então, na busca por lugares seguros, que sirvam de anteparos a uma individualidade que evite qualquer relação com o mundo exterior e os perigos que esse possa representar.

Também um tempo que faz surgir ações de demarcação de espaços cativos, particulares, restritos dentro da cidade, ao mesmo tempo em que se faz proferir e professar políticas que se dizem direcionadas a facilitar a mobilidade e circulação. Como compreendê-las? Aqui, se aposta que, entre a constatação de Benjamin e a estruturação de formas (nem tão) novas de segregação, se produzem fronteiras que barram, delimitam e estancam as possibilidades de experimentação dos viventes na cidade, mas também novas configurações desses limites, as quais, por outras vias, também interditam e esvaziam os sentidos anteriormente atribuídos aos ritos e passagens.

Isso a que denominamos fronteira ou limite - em alemão grenze e em latim finis, confinis - para Benjamin (2006), designará uma linha que pode variar quanto à extensão ou espessura e que não pode ser transposta impunemente. Ou seja, a fronteira tem por princípio de funcionamento conter e manter algo, evitando seu transbordamento, definindo seus limites, dando-lhe um contorno ou atribuindo-lhe limitações. Inspirados nessa concepção de Benjamin, podemos dizer que estabelecer fronteiras pode ser defınida como o ato de "desenhar um traço ao redor de algo para Ihe dar uma forma bem definida e, portanto, evitar que esse algo, por assim dizer, se derrame sobre suas bordas" (Gagnebin, 2014 p. 35).

Por seu turno, o conceito de limiar, soleira ou umbral (Schwelle) se inscreve noutro registro que se notabilizaria por permitir que se transite, com considerável facilidade, de um dado lugar a outro diferente e, por vezes, mesmo oposto. Desse modo, conquanto também separe dois territórios, diferente da fronteira, o limiar permite transitar por entre eles. Uma transição, dirá Gagnebin (2014), que será de duração e extensão espacial variáveis. Ou seja, enquanto a fronteira, entendida como linha ou traço limítrofe, acenaria para uma relação estrita com o espaço, o limiar se refere à relação que os corpos estabelecem com esses espaços, mas também temporaliza essa relação, tornando as passagens dependentes do tamanho do limiar, da rapidez, lentidão, agilidade, indiferença ou respeito àquele que transita.

O limiar é, assim, uma marca que atrai pelo que promete (em Walter Benjamin, "incita uma reflexão sobre o secreto") diferente da fronteira, que é um lugar que pode assustar pelo que esconde, o desconhecido do outro lado; o limiar é uma linha (ampla, mais uma "zona", como diz Benjamin) de passagens múltiplas, a fronteira é uma linha única de barragem, num caso mais traço de união, no outro de separação; enquanto a fronteira é muitas vezes apenas um lugar burocrático, o limiar é o lugar onde ferviIha a imaginação (Barrento, 2013, p. 121)

Algumas observações a respeito dessa definição apresentada por João Barrento: o limiar como uma zona. Definição que, inclusive, abarca a conotação de prostíbulo que o termo pode assumir no português do Brasil. Aliás, recordemos aqui, se é no contexto das Passagens sobre prostituição e jogo que Benjamin subleva a discussão sobre a nossa atual carência de experiências limiares, dirá ele também das formas como a prostituição lida e produz limiares, alimentando as portas da imaginação daqueles que a procuram e daquelas que a praticam. Zona - o limiar e o puteiro - que lembra fluxos e atravessamentos, mas também, ou primordialmente, desejo. Um e outro, "morada dos sonhos" (Benjamin, 2006, p. 535).

A partir das contribuições de Benjamin, Baptista (2010) ressalta que residiria nisso a efetividade do ideário capitalista de ultrapassar os limites do econômico, forjar sonhos e modos de despertar, e, com isso, fomentar não somente a barbárie da cultura, mas também a possibilidade de fluxo e movimento na e da cidade:

movimentos sem forma definida ou destituídos da previsibilidade do tempo, nos dariam a chance de sair dos limites da soberania da subjetividade privatizada. (...) mobilidade sugerida [que] teria a leveza do escape do eu dos seus herméticos limites, propiciada por encontros e por conexões nunca esgotadas. Leveza talvez dolorosa, como os paradoxos da modernidade, mas desafiadora para as existências sedentárias (Baptista, 2010, p. 214-215).

Nesses termos, podemos dizer que a atribuição do limiar 
como correspondente à ligação ou passagem porosa entre dentro e fora serve de demonstrativo do pensamento como campo de forças inacabado, residual, transitório. Exercício de pensamento que recorre à experiência, fazendo-se leve e demorado, recolhendo estilhaços e farrapos, sem pretensão às conclusões peremptórias, resguardando-se a possibilidade de passagem, de produção de desvios, suspensão de certezas e novos atravessamentos (Rizek, 2012).

É nesse sentido que "Rua de Mão Única" ou "O Livro das Passagens" podem ser lidas como montagem - uma cartografia de limiares:

uma aglomeração aparentemente caótica de textos, fragmentos, cartas, experiências, relações, sem limites nem sistema aparente, estrutura-se descontínua e contraditoriamente uma figura da ambiguidade, um perfil flutuante que se desdobra ad infinitum em linhas paralelas e tonalidades alternantes" (Barrento, 2012, p. 44).

Não obstante esses aparentes desalinhos, acrescenta Barrento (2013), Benjamin faz desses desarranjos de sua obra inventários inconclusos de um sem número dessas passagens e seus fluxos. Assim, o limiar se refere também à recusa aos sistemas conceituais reificados de que dispomos, para, em seu lugar, recorrermos a um modo de proceder que não separe o pensar da forma do pensamento, ao tempo em que se recorre sempre à escolha de zonas-limite e passagens transversais aos saberes instituídos (Barrento, 2012).

É nesse sentido que a obra benjaminiana compõe constelações de limiares que se transformam em lugares de vida e de pensamento escrito, enquanto as fronteiras acabariam por indicar um lugar de morte. Lugar de vida cuja efetivação sugere a necessidade de reativar a função da experiência, pondo-se à cata dos trapos, recolhendo estilhaços e resíduos deixados pelo homem em sua vivência moderna na cidade (Benjamin, 2012).

Um exercício que, afirma Beherns (2010), implica uma relação desse homem com seu tempo que suprima qualquer primazia do aqui e agora, diferente da vontade moderna de experimentar a vida a-historicamente, sempre remetida à efemeridade do momento, sempre como agonística insaciável pelo novo. Aqui ganha relevo a crítica benjaminiana à produção, já no alvorecer do século XX, de uma lógica de aceleração da vida, a qual agiria pelo encurtamento dos momentos de transições e passagens ao máximo, tendo em vista a maximização da produção de novas mercadorias e otimização do tempo daqueles que as consomem (Gagnebin, 2014).

Tal processo parece amplificado em nossos dias, na medida que a crise dos ritos de passagem, mencionada por Benjamin, parece acenar para uma sobrecarga de informações e ruptura das fronteiras (a partir da conjuração de um mundo globalmente conectado), ao tempo em que isso descambaria numa vertiginosa sucessão de impulsos informacionais que, ao mesmo tempo em que estimulam nossa percepção, também sufoca os intervalos, instantes e possíveis paradas nas quais poderiam parar e recobrar o fôlego (Benjamin, 1984; Ribeiro \& Capanema, 2016).

Do mesmo modo, sugere ainda Beherns (2010), tampouco se trata de uma relação de desprendimento ou desterritorialização total que redundaria na percepção ou vivência de deslocamento do homem em relação ao mundo. Ou seja, se não é num tipo de presenteísmo desregrado que encontraremos as experiências limiares, também não o será em um "utopos", entendida por ele no sentido do "não lugar", que elas poderão ser encontradas, experimentadas, compartilhadas. Dessa maneira, como zona de trânsito, o limiar se constituiria num lugar e tempo intermediários: por um lado, longe de se afirmar univocamente devedor de um now. Por outro, sendo não afırmativo de um here, para Baherns (2010), o limiar residiria, enfim, em um "lugar nenhum que oscila entre o now-here e o no-where" (p. 96).

Considerando essa peculiar ambiguidade, Beherns (2010) aponta ainda que, entendido como soleira (Türschwelle), um limiar poderia designar duplamente tanto uma passagem quanto um obstáculo (visível ou invisível). Assim, tem-se a possibilidade de interpretá-lo, por exemplo, com uma última zona de proteção anterior a um perigo, mas também como a última barreira a impedir o alcance da realização ou felicidade. Temos, nesses termos, a estranha conceituação do limiar como "uma passagem e a mesmo tempo a barreira dessa passagem, uma passagem que não se pode passar sem nada nem menos" (p. 102).

\section{LIMIARES ONDE NADA ACONTECE}

Acenamos aqui alguns dos eventuais desdobramentos desse aspecto paradoxal. 0 mais fundamental deles já fora aqui apresentado, referindo-se a espaços intermediários, indefinidos. Isto é, o limiar como algo que comporta mudança, transição, fluxo etc. Mas, há também que se mencionar um outro, possivelmente tão severo quanto: aquele que pode descambar na perda de seu caráter transitório e inapreensível, para, ao contrário, constituir zonas limiares fixadas na dúvida, apreensão ou imobilidade.

Nessa conjuntura, teríamos um limiar rendido ao "tempo do consumo", conforme aponta (Beherns, 2010). Ou seja, um tempo que recobra as forças de um capital que seduz pela circulação de novas mercadorias, na medida que instaura um universalizante nivelamento que ameaça petrificar qualquer traço sublime sob a forma de uma nova e lucrativa mercadoria (Gagnebin, 2014). 


\section{H* INTERACÃO EM LF PSICOLOGIA}

Nesse encolhimento de experiências liminares, é como se houvesse portas que não separam, que não levam a lugar nenhum. As portas se escancaram, mas não podemos sair do lugar. De corredor em corredor, de limiar em limiar, de sala de espera em sala de espera, acabamos por esquecer nosso destino, o alvo que em algum momento tínhamos desejado. Esses limiares - lugares de transição se transformam em lugares de detenção. As grandes questões - as questões sobre as passagens - ficam ali presas ao se transformarem em problemas administrativos, em problemas de gestão em que não há mais escoIha, mas acomodação, gestão sobre vivos e mortos, sobre corpos que vagueiam em limiares indefinidos e inchados, quase figurações do humano (Rizek, 2012, p. 34).

Tal crítica se alinha à afirmação proferida por Jean Marie Gagnebin, quando, recorrendo à produção de uma massiva dimensão apolítica da vida nos campos de concentração, essa autora vai sustentar que a despeito da nossa dificuldade, apontada por Benjamin, em conhecer e viver experiências limiares, o que se constataria atualmente seria uma incapacidade ainda mais aterradora: a de que, por vezes, o limiar parece ter perdido sua função, operando agora não mais como fluxo, mas como abnegação absoluta de tomarmos partido ou de nos lançarmos à experimentação fora do casulo petrificante da indiferença e da indiferenciação. Como afirma Gagnebin (2014), um limiar caricato que perde sua aura de espaço-tempo, "como se o avesso da mobilidade trepidante da vida moderna fosse um não poder nunca sair do lugar" (p. 45).

Institui-se, como elemento fundamental à análise da aparente derrocada das experiências limiares, portanto, a constatação desses autores de que tais experiências têm sido preteridas por um progressivo achatamento de algumas diferenças que modulariam a existência humana - tais como as que sustentariam as diferenças entre vida e morte, profano e sagrado, público e privado.

Vivemos tal qual o personagem homônimo do belo e sufocante Filho de Saul, filme húngaro do diretor Lazló Nemes. Nele, a barbárie do nazismo é mostrada de modo bem peculiar. Na maior parte do tempo, a câmera apresenta desfoque de fundo e persegue o rosto de Saul em quase todo o filme. Não se trata de pacificar as imagens, pelo contrário, todo o horror do nazismo é apresentado ao espectador a partir das expressões e comportamento da personagem principal. Ele, não tem expressões, não parece sentir, não sorri, não chora, não se assusta, quase não fala. Essa sua aparente indiferença, experimentada no limiar entre a vida e a morte que representa a vida nua do campo, nos faz quase que sentir raiva de Saul, se não compreendemos que ele é realização do projeto nazista de despolitização total das existências.

$\mathrm{Na}$ esteira das percepções apontadas por Primo Levi acer- ca da produção de um corpo morto em vida nos campos de concentração nazistas, O Filho de Saul apresenta seu personagem principal como lançado entre a indiferença apaticamente aterradora de ter que lidar com toda sorte de atrocidades, enquanto tenta a todo custo enterrar o corpo de um jovem que ele toma como sendo seu filho. Assim, como existência cinzenta, quase que totalmente dessensibilizada do que ocorria consigo e com os outros, o homem vagueia por entre atividades que, embora apresentem todo o horror da experiência com o nazismo, são executadas com uma inexpressiva desídia, como se limpar o chão salpicado com o sangue de montanhas de judeus mortos ou jogar as cinzas provenientes das fornalhas que incineravam os corpos fossem meras atividades rotineiras da vida humana.

Ou seja, se o limiar incita o transbordamento ou a resistência às máquinas de captura, com Saul se evoca uma existência que se vê parada no limite entre a vida e a morte nem em um, nem no outro, estagnado e só. Nesse sentido, poderíamos falar aqui de uma existência limiar ou fronteiriça, mas atualizando tal terminologia para mencionar a produção capitalística de vidas que não mais transbordam. Ou, melhor posto, ainda o fazem, porém como avatares de uma autoafirmativa e autorreferencial subjetividade aprisionada que evita ao menos roçar nos desafios e vicissitude da vida cotidiana. Como rechaçamos o encontro com tudo que nos possa macular, estaríamos, enfim, presos num limiar do qual saímos apenas para exercitar uma catarse que, em vez de fazer tremer os contornos da identidade, serve para apaziguá-la, para evitar a exposição ao perigo. Uma indiferença que, quando transformada em indignação, não transtorna, tampouco surpreende (Baptista \& Barbosa, no prelo).

Temos, nesses termos, a concepção de que o modo dominante de gestão da vida atualmente parece ter capitalizado muitos dos processos que poderíamos relacionar ou compreender como anteriormente resistentes. Uma existência que, na perspectiva de ampliação ao máximo de sua sobrevida individual, se mostra sedento pelo efêmero do gozo instantâneo, ao tempo em que não se deixa "contaminar" pelo estranho e evita praticar o exercício político na cidade como confrontamento, desentendimento, conversa entre desiguais (Rancière, 1996).

Assim, nessa outra conjuntura, aquilo que era visto como - talvez - possibilidade de resistência a essa fronteira-disciplina, ou seja, a possibilidade de trânsito, fluxo, e mobilidade na cidade, por vezes também passará a constituir uma das formas com que se pode efetivar a normalização ou controle. Agora, sem necessariamente recorrer ao escrutínio do espaço e tempo conforme o modelo disciplinar. Assim, se por um lado ainda se levantam e se sustentam fronteiras que delimitam, controlam e impedem os fluxos, por meio do controle e 
gestão político e jurídica do território - tais limites aparecendo sob a forma de muros de contenção, criação de espaços, zoneamento etc.; por outro lado, muitos desses controles passam a ser efetuados e organizados a partir de princípios mais sutis, os quais tornam difícil - a princípio - reconhecer seus contornos, bordas, limites (Haesbaert, 2014). O que resta de limiar, então, quando parte de sua potência parece ter sido usurpada? O que, apesar de tudo, pode um limiar ainda?

\section{LIMIARES DO AINDA VIVO}

Uma resposta possível, amparada nalgumas ideias de Michel Foucault, deve ressoar em nós, convidando ao esforço de junto ao proposto por Benjamin, não apenas opor limiares e fronteiras, mas, liminarmente, nos constituir "nas fronteiras". Isto é, tomar como atitude (êthos filosófico) o exercício de não ser nem uma coisa, nem outra: "Esse êthos filosófico pode ser caracterizado como uma atitude-limite. Não se trata de um comportamento de rejeição. Deve-se escapar à alternativa do dentro e do fora; é preciso situar-se nas fronteiras" (Foucault, 2015, p. 364)

Frase dispersa, jogada por Foucault ao longo de seu texto sobre o lluminismo e que sintetiza a ideia desse autor acerca do modo como podemos constituir resistências e a fabricação de outros modos de experimentação da vida. É com ela que Foucault propõe a colocação do presente como acontecimento filosófico, abrindo a possibilidade de se interrogar a respeito da atualidade daquele que pergunta e da qual faz parte. 0 autor francês se refere à prática de uma relação de se debruçar sobre o tempo, com o intuito de conhecê-lo para, a partir daquilo que há de singular nele, podermos transmutálo. A isso denominará de ontologia de nós mesmos, ontologia do presente ou analítica de nós mesmos (Foucault, 1984a; 1984b; 2015).

Ele irá identificar a filiação desse perguntar-se sobre si mesmo a uma das duas grandes tradições críticas da filosofia moderna fundada por Kant. Por um lado, uma "analítica da verdade", tradição filosófica que colocava a questão das condições sobre as quais um conhecimento verdadeiro é possível; por outro, uma interrogação crítica que aquele perguntar-se inaugura. Uma ontologia do presente ou analítica do presente.

Ao recorrer a algumas das ideias do poeta Charles Baudelaire acerca da modernidade, Foucault (2015) irá caracterizar essa ontologia de nós mesmos a partir de alguns fundamentos. O primeiro deles, certa heroificação do presente. Para Baudelaire, a modernidade contém aquilo que é fugidio, contingente; ela comporta um sentimento de incerteza da novidade, assim como escapa a algumas tradições. O homem que é moderno não é aquele que se deixa levar pela vertigem daquilo que é novo, mas sim aquele que assume determinada atitude diante do movimento desse novo, das rupturas com as tradições. Dessa forma, não se espera do moderno passividade àquilo que se movimenta em direção ao diferente, mas tentativas de captar no presente o que há de eterno nele, o que concerne àquele tempo, para assim Ihe heroificar.

Tal heroificação, assim dita, não significa puramente um esforço de perpetuação ou sacralização do presente, em detrimento do passado ou do futuro. É preciso, ressalta Foucault que ela seja irônica. Ou seja, versar sobre um trabalho de tomar o tempo exatamente no que ele é, para, a partir do que já concebemos como pertencente ao presente, imaginálo diferente, imaginar o que ele ainda não é e, assim, transfigurá-lo. Do mesmo modo, tal transfiguração do presente não diz respeito a rejeitar o que já existe, nem à construção utópica de um tempo novo ideal, mas, por meio da obstinada imaginação daquilo que não temos, partindo exatamente do real, pensarmos em transfigurações também reais, em outras possibilidades para o presente. Assim, a partir do reconhecimento das condições do nosso tempo, se busca enxergar no presente o "ponto de transição" (p. 337) para novas conjeturas. Proposições que remetem ao esforço em reconhecer o que o presente (o nosso tempo atual) emana de passado e o que se organiza para dar base a um futuro. Do mesmo modo, é perceptível uma necessidade de enxergar o presente como a ferramenta essencial de alteração das condições de vida e existência, pela ativação, nele, de possibilidades outras de relação com o mundo e consigo mesmo.

Transmutado para a análise dos limiares, esse pôr-se nas fronteiras advogará que, se há uma crise dessas experiências que as faz desaparecer progressivamente ou serem esvaziadas de seu propósito, há que se perceber que esse contexto abriga também a possibilidade de surgimento de experiências de desvio ou contornamento (Foucault, 2009; Haesbaert, 2014). Ou seja, outras formas de estar, ocupar e fazer funcionar espaços e práticas que tem o poder de justapor em um só lugar real vários espaços, vários posicionamentos, por si só incompatíveis. Heterotopias, dirá Foucault (2009), que se põem em funcionamento quando aquele exercício ontológico leva a uma espécie de ruptura absoluta do homem com seu tempo tradicional, com aquilo que parece não ter mais jeito ou que está finalizado. É a partir delas que, supomos, se torna inteligível compreender os atuais matizes que caracterizam as fronteiras e limiares, da mesma maneira em que se pode aventar possibilidades de operá-los para além desses registros instituídos.

Reativa-se, assim, certo elemento intempestivo e destrutivo do limiar que nos obriga a operar uma empiria sensível da cidade. Qual seja, a de reconhecê-la como pulsante, heterogênea, constitutiva e constituinte de outros espaços, frontei- 


\section{-4: INTERACÃO EM ET PSICOLOGIA}

ras e mapas que nunca estão plenamente finalizados. Modo de vida contingente, por certo, mas convicto em afirmar a força daquilo que é mais elementar: a cidade ainda vive. Mediante a este ainda, o artesanato, ou produção de outras subjetividades poderão pôr em análise o torpor paralisante de um mundo sem saída, da morte da cidade; inquira o eu soberano artífice de criatividades infinitas, sempre em dívida. 0 ainda da conflitualidade da vida cotidiana a impedir a previsibilidade do significado esperado, a conclusão da narrativa. 0 ainda não do inacabamento da história, que se recusa a se fazer crente das subjetividades herméticas e prontas. Na potente precariedade do humano, afirmada na desestabilizadora presença da alteridade, a cidade ainda vive.

\section{CONTRIBUIÇÕES DE CADA AUTOR:}

L.B. e L. A.B. participaram conjuntamente das fases de conceituação, Redação inicial (rascunho) e também são responsáveis pela redação final.

\section{DECLARAÇÃO DE CONFLITO DE INTERESSES:}

Os autores declaram que não há conflitos de interesse no manuscrito submetido.

\section{REFERÊNCIAS}

Baptista, L. A. (2010). Impactos da (i)mobilidade na produção da subjetividade. Em Conselho Federal de Psicologia. Psicologia e mobilidade: 0 espaço público como direito de todos. (pp. 213-219). Brasília: Autor.

Barbosa, M., \& Baptista, L. A. (no prelo). O incômodo das imagens: limiares e fronteiras da diferença. Revista ECOS - Estudos Contemporâneos da Subjetividade, 2018.

Barrento, J. (2012). Walter Benjamin: Limiar, fronteira e método. Olho d'água, 4(2), 41-51.

Barrento, J. (2013). Limiares: Sobre Walter Benjamin. Florianópolis: UFSC.

Beherns, R. (2010). Seres limiares, tempos limiares espaços limiares. Em G. Otte, S. Sedlmayer, \& E. Cornelsen (Orgs), Limiares e passagens em Walter Benjamin. (pp. 93-112) Belo Horizonte: UFMG.

Benjamin, W. (1984). Origem do drama barroco alemão. São Paulo: Brasiliense.

Benjamin, W. (2004). Rua de sentido único. Lisboa: Assírio \& Alvim.

Benjamin, W. (2006). Passagens. Belo Horizonte: UFMG; São Paulo: Imprensa Oficial do Estado de São Paulo
Benjamin, W. (2012). O narrador: Considerações sobre a obra de Nicolai Leskov. Em Obras escolhidas: Magia e técnica, arte e política. (8 ${ }^{a}$ ed., pp. 213-240). São Paulo: Brasiliense.

Foucault, M. (1984a). Qu'est-ce que les Lumières? In: P. Rabinow, The Foucault Reader. (pp. 32-50). New York: Pantheon Books.

Foucault, M. (1984b). Qu'est-ce que les Lumières? In: Dits et escrits IV (pp. 679-689). Paris: Éditions Gallimard.

Foucault, M. (2009). Outros espaços. In: M. Foucault, Ditos e Escritos III: Estética: literatura e pintura, música e cinema. (pp. 411-422). Rio de Janeiro: Forense Universitária.

Foucault, M. (2015). O Que São as Luzes? In: M. Foucault, Ditos e Escritos II: Arqueologia das Ciências e História dos Sistemas de Pensamento. ( ${ }^{a}$ ed., pp. 351-368). Rio de Janeiro: Editora Forense Universitária.

Gagnebin, J. M. (2014). Limiar: Entre a vida e a morte. Em Limiar, aura e rememoração: ensaios sobre Walter Benjamin. (pp. 33-50). São Paulo: Editora 34.

Haesbaert, R. (2014). Viver no limite: Território e multi/transterritorialildade em tempos de in-segurança e contenção. Rio de Janeiro: Bertrand Brasil.

Rancière, J. (1996). O desentendimento: Política e filosofia. São Paulo: 34.

Ribeiro, D. M., \& Capanema, L. X. L. (2016). Limiares e Fronteiras na Arte: Um estudo sobre a experiência estética em Walter Benjamin. Interin, 21(2), 05-22.

Rizek, C. S. (2012). Limites e limiares: Corpo e experiência. ReDObRA, 3(10), 33-39.

Data de submissão: 31/10/2017 Primeira decisão editorial: 29/01/2018 Aceite em 12/03/2018 